\title{
Biodiversity and biotechnological applications of halophilic microbes for sustainable agriculture
}

\author{
Ajar Nath Yadav ${ }^{1 *}$, Anil Kumar Saxena ${ }^{2}$ \\ 'Department of Biotechnology, Akal College of Agriculture, Eternal University, Sirmour-173101, India, ${ }^{2}$ ICAR-National Bureau of Agriculturally Important \\ Microorganisms, Kushmaur, Mau Nath Bhanjan, Mau-275103, India.
}

\section{ARTICLE INFO \\ Article history: \\ Received on: July 12, 2017 \\ Accepted on: August 22, 2017 \\ Available online: January 17, 2018}

Key words:

Biodiversity,

Halophilic microbes,

Plant growth promotion,

Plant-microbe interactions,

Sustainable agriculture.

\begin{abstract}
Extreme saline environments represent unique ecosystems for novel microbial biodiversity. The salt-tolerant microbiomes have been reported from diverse saline habitat. The biodiversity of salt-tolerant microbes showed the presence of different groups of microbes including Actinobacteria, Bacteroidetes, Euryarchaeota, Firmicutes, Proteobacteria, and Spirochaetes. The salt-tolerant plant growth promoting (PGP) microbes such as Ammoniphilus, Arthrobacter, Azospirillum, Bacillus, Brevibacillus, Brevibacterium, Haloarcula, Halobacillus, Halococcus, Haloferax, Halolamina, Halomonas, Halorubrum, Haloterrigena, Lysinibacillus, Marinobacter, Marinospirillum, Oceanobacillus, Paenibacillus, Penicillium, Pontibacillus, Pseudomonas, Sediminibacillus, Sporosarcina, Streptomyces, Thalassobacillus, and Thermonema have been isolated and characterized for plant growth under the salinity stress. The halophilic microbes have ability to produce phytohormones (indole acetic acids, gibberellic acids, and cytokinin), solubilize and bind nutrients (phosphorus, potassium, zinc, and siderophores), besides eliciting plant defense reactions against pathogens, also help in plant growth under harsh saline environments. The halophilic PGP microbes increase the plant growth, yields, and nutrient uptake under the saline condition. In the present review, the biodiversity of halophilic microbes from diverse ecosystems, its functional PGP attributes and mechanisms of action for amelioration of salt stress, plant growth, and soil health for sustainable agriculture have been discussed. The salt-tolerant microbes with multifarious PGP attributes could be applied for plant growth and ameliorations of salt stress.
\end{abstract}

\section{INTRODUCTION}

Soil salinity is one of the major limiting factors for plant growth and its productivity worldwide. The research on salt tolerance microbiomes have been increased to improve crop growth and yield for sustainable agriculture. Salinity is a natural feature of ecosystems in arid and semiarid regions and can also be induced by anthropogenic activities. Nearly $20 \%$ of the world's cultivated lands are affected by salinity, which is responsible for significant crop production losses. The hypersaline environment is one of the most extreme habitats with respect to the sodium chloride concentration. The salt concentrations in hypersaline habitats range from $>15 \%$ to saturation, with $\mathrm{pH}$ values from acidic to alkaline ( $\mathrm{pH}$ 6-11). The microbiomes of various saline environments are salt-loving microbes, with the capacity to tolerate abiotic stress of salinity $(2.57-5.48 \mathrm{M} \mathrm{NaCl})$. Halotolerant microbes specifically require salt for growth and development under the normal and saline conditions. The salt-loving microbes can be grouped as true halophiles (15-30\% NaCl), moderate halophiles (3-15\% M NaCl), and slight halophiles $(1-2 \% \mathrm{NaCl})[1]$.

*Corresponding Author:

Ajar Nath Yadav,

Eternal University, Baru Sahib, Himachal Pradesh, India.

Email:ajar@eternaluniversity.edu.in
Halophilic/halotolerant microbes have been isolated from diverse hypersaline environments such as solar salterns, hypersaline lakes, the Dead Sea, hypersaline microbial mats, and underground salt deposits. The salt-tolerant plant microbiomes (epiphytic, endophytic, and rhizospheric) have been sort out and characterized for tolerance to abiotic stress of salinity and other beneficial attributes worldwide [2]. The salt-tolerant microbes have been discovered from different phyla including Actinobacteria, Bacteroidetes, Euryarchaeota, Firmicutes, Proteobacteria, and Spirochaetes. Halophilic microbes such as Ammoniphilus, Arthrobacter, Azospirillum, Bacillus, Brevibacillus, Brevibacterium, Haloarcula, Halobacillus, Halococcus, Haloferax, Halolamina, Halomonas, Halorubrum, Haloterrigena, Lysinibacillus, Marinobacter, Marinospirillum, Oceanobacillus, Paenibacillus, Penicillium, Pontibacillus, Pseudomonas, Sediminibacillus, Sporosarcina, Streptomyces, Thalassobacillus, and Thermonema have been isolated and characterized for plant growth promotion. The plant growth promoting (PGP) attributes included biological nitrogen fixation; 1-aminocyclopropane-1-carboxylate (ACC) deaminase activity; solubilization zinc, potassium and phosphorus; production of ammonia, hydrogen cyanide, siderophores (Fe-chelating compounds), phytohormones (cytokinin, gibberellic acids, and indole acetic acids); and other secondary metabolites. In the present review, the biodiversity of halophilic microbes from diverse ecosystems, its functional PGP attributes and mechanisms of action for amelioration of salt stress, 
plant growth, and soil health for sustainable agriculture have been discussed.

\section{BIODIVERSITY OF HALOPHILIC MICROBES}

Microbial research in saline environments (solar salterns, hypersaline lakes, the Dead Sea) has fascinated the curiosity of scientists due to biotechnological application of salt-tolerant microbes in agriculture, industry, and medicine. The salt-tolerant microbes could be applied as biofertilizers under saline condition for growth, yield, and soil

health for sustainable agriculture. The novel and efficient enzymes producing halophilic microbes may be used in different industrial processes. There are many novel species of halophilic microbes including Actinopolyspora mortivallis [3], Halothermothrix

orenii [4], Natrinema versiforme [5], Halomonas marisflavae [6], Bacillus marisflavi [7], Arcobacter halophilus [8], Nesterenkonia aethiopica [9], Aquisalimonas asiatica [10], Amycolatopsis halophila [11], Pontibacillus yanchengensis [12], Streptomyces chilikensis [13], Prauserella isguenensis [14], Marinirhabdus gelatinilytica [15], and Haloprofundus marisrubri [16], which have been sorted out from crops growing under saline conditions, saline lakes, and hypersaline soils worldwide.

The hypersaline region represents hot spots of biodiversity of several novel and efficient salt-tolerant microbial (archaeal bacterial and fungal) species which have been reported from different hypersaline. Archaea is one of the most abundance microbes reported from extreme saline and hot springs environments. There are very few reports of archaea as associated with plants such as maize, rice, and halophytic plant (Abutilon, Cressa, Sporobolus, and Suaeda nudiflora) [17-19]. Archaea have been reported as unculturable from maize [20] and rice crop [21], whereas culturable archaea have been reported from Abutilon, Cressa, Sporobolus, S. nudiflora [22]. The most dominant microbes belong to domain Eubacteria which included different genera such as Alkalibacillus, Amphibacillus, Amycolatopsis, Arthrobacter, Bacillus, Brevibacterium, Corynebacterium, Exiguobacterium, Haloactinomyces, Halobacillus, Haloglycomyces, Halomonas, Lysinibacillus, Microbacterium, Micrococcus, Oceanobacillus, Oceanobacillus, Paenibacillus, Paraliobacillus, Planococcus, Pontibacillus, Pseudomonas, Rhodococcus, Salinibacillus, Sediminibacillus, Sporosarcina, Staphylococcus, Streptomonospora, Streptomyces, Tenuibacillus, Thalassobacillus, and Virgibacills have been reported from diverse saline environments. Along with bacterial isolates, the halophilic fungi such as Alternaria, Aspergillus, Cladosporium, Debaryomyces, Hortaea, Myrothecium, Penicillium, Piriformospora, Saccharomyces, Stemphylium, Sterigmatomyces, Trichoderma, Ulocladium, and Wallemia have been reported from the diverse hypersaline environment and hypersaline lakes worldwide [17,23,24]. Microbiome of saline environments, especially halophilic fungi, has become one of the richest bioresources for industrially important molecules and enzymes. Among different groups of fungi, the isolated from deep sea are most important in pharmaceutical industry, due to the production of secondary metabolites under the harsh saline conditions. The hypersaline habitats are only beginning to be investigated for bioactive natural products.

Halophilic microbes have been reported from different phylum including Actinobacteria, Bacteroidetes, Euryarchaeota, Firmicutes, Proteobacteria, and Spirochaetes (Fig. 1). Among different groups of bacteria, Actinobacteria are most dominant and are ubiquitous in nature and have been isolated from diverse extreme environments (extreme temperatures, $\mathrm{pH}$, salinities, pressure, and drought) and associated with plant growing in different habitat. The rhizospheric actinobacteria have been reported, biochemically characterized, and identified using $16 \mathrm{~S}$ rRNA gene sequencing. Based on a comprehensive literature analysis, members of phylum actinobacteria have been reported from different genera such as Acidimicrobium, Actinomyces, Arthrobacter, Bifidobacterium, Cellulomonas, Clavibacter, Corynebacterium, Frankia, Microbacterium, Micrococcus, Mycobacterium, Nocardia, Propionibacterium, Pseudonocardia, Rhodococcus, Sanguibacter, and Streptomyces from saline habitat $[25,26]$.

The members of Firmicutes are widely dispersed in nature, easy to multiply, have a long shelf life when sporulated, and are nonpathogenic. Among Bacillus and Bacillus-derived genera, Bacillus thuringiensis, Bacillus subtilis, Bacillus pumilus, Bacillus mycoides, Bacillus megaterium, and Bacillus firmus are ubiquitous in rhizosphere saline soil $[1,27,28]$. The genus Bacillus consists of a heterogenic group of endospores forming Gram-positive rods, which survive for extended periods under adverse environmental conditions due to endospores. The phylum proteobacteria are Gram-negative bacteria which included $\alpha / \beta / \gamma / \delta$-proteobacteria, which has been reported from different saline environments. Among proteobacteria, $\alpha$-proteobacteria grows at very low levels of nutrients and includes agriculturally imperative bacteria capable of inducing Azospirillum, $\mathrm{N}_{2}$-fixation in symbiosis with plants. The $\beta$-proteobacteria is highly metabolically diverse and contains chemolithoautotrophs, heterotrophs, and photoautotrophs, whereas the $\gamma$-proteobacteria is the largest class in terms of species Pseudomonas and Azotobacter [17,29].

\section{HALOPHILIC MICROBES FOR SUSTAINABLE AGRICULTURE}

Soil salinity is a major problem facing the agricultural production in many fields and soil infertility in the treatment or the regions due to the presence of high concentrations of salt. The excess of soluble salt is present in saline soil and $\mathrm{Na}+$ with negative-charged clay particles present in hypersaline soil. The growth of plant/crops has been inhibited due to the presence of high concentration of sodium salt in the saline soil which occurs through natural or human-induced processes. The natural salinity results from the accumulation of salts over a long period of time due to weathering process. Accumulation of salt such as sodium chloride, calcium chloride, and magnesium chloride have been done continuous by weathering process (breaks down rock and releases soluble salts). The plant microbiomes have been selected by plants itself by producing different nutrients into nearby environments. The beneficial and efficient microbes have attached to roots by different plant, due to their root exudates. The epiphytic microbes have attached to phyllosphere part of plant due to secretion of diverse sticky substances by plants. Thus, the plantmicrobes interaction has been developed, and microbial community utilized the constituents of exudates as sources of energy [2,30].

The microbiomes isolated from crops growing in saline ecosystems are able to promote the plant growth. The plant microbiomes have been reported as epiphytic, endophytic, and rhizospheric and have been characterized for plant growth promotion under in vitro and in vivo condition of salinities stress. The PGP microbes belonged to different genera such as Achromobacter, Azotobacter, Bacillus, Burkholderia, Methylobacterium, Micrococcus, Micromonospora, Pantoea, Pseudomonas, and Streptomyces as epiphytic microbes; Achromobacter, Bacillus, Burkholderia, Microbiospora, Micromonospora, Nocardioides, Pantoea, Planomonospora, Pseudomonas, Streptomyces, and Thermomonospora as endophytic microbes; and Azospirillum, Alcaligenes, Arthrobacter, Acinetobacter, 


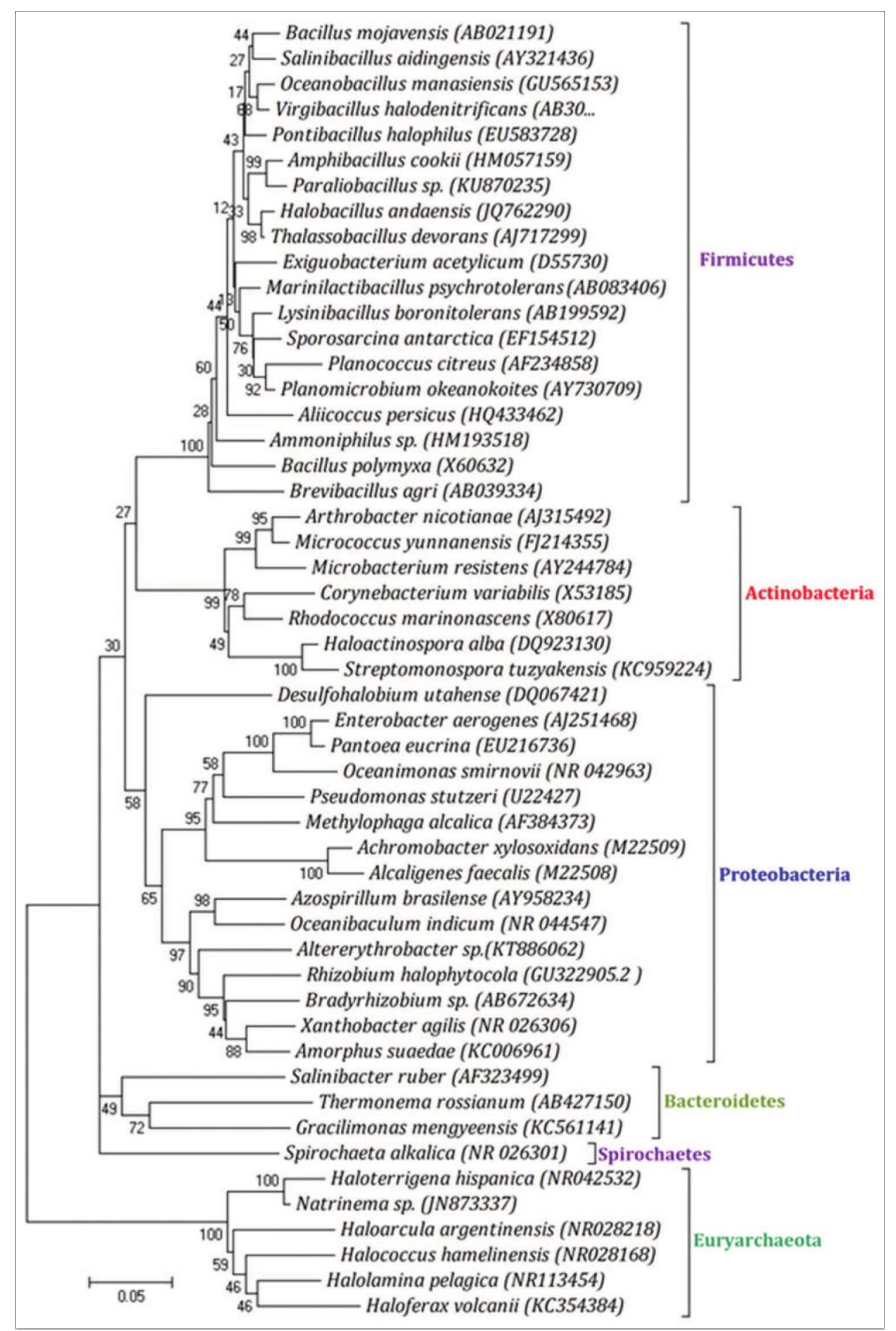

Fig. 1: Phylogenetic tree showed the relationship among halophilic microbes. 16S rRNA gene sequences obtained from NCBI database. The sequence alignment was performed using the CLUSTAL W program, and trees were constructed using maximum likelihood method with algorithm using MEGA4 software. One thousand bootstrap replicates were performed. Bootstrap values are indicated on the branches.

Bacillus, Paenibacillus, Burkholderia, Enterobacter, Erwinia, Flavobacterium, Methylobacterium, Pseudomonas, Rhizobium, and Serratia as rhizospheric microbes from crops growing in diverse agroecosystems $[18,26,31,32]$.

The plant microbiomes can promote plant growth directly by the production of phytohormones (indole acetic acids, gibberellic acids, and cytokinin), solubilization and bindings of nutrients (phosphorus, potassium, zinc, and siderophores), biological nitrogen fixation, and ACC deaminase activity. In another plant growth, mechanisms of in-direct by the production of ammonia, hydrogen cyanide, siderophore (Fe-chelating compounds), and other secondary metabolites which elicits plant defense against different plant pathogens also help in plant growth under harsh saline environments $[26,32,33]$ (Table 1). The 
Yadav and Saxena: Biodiversity and biotechnological applications of halophilic microbes 2018;6(1):48-55

Table 1: Role of halophilic microbes in plant growth promotion under the saline environments.

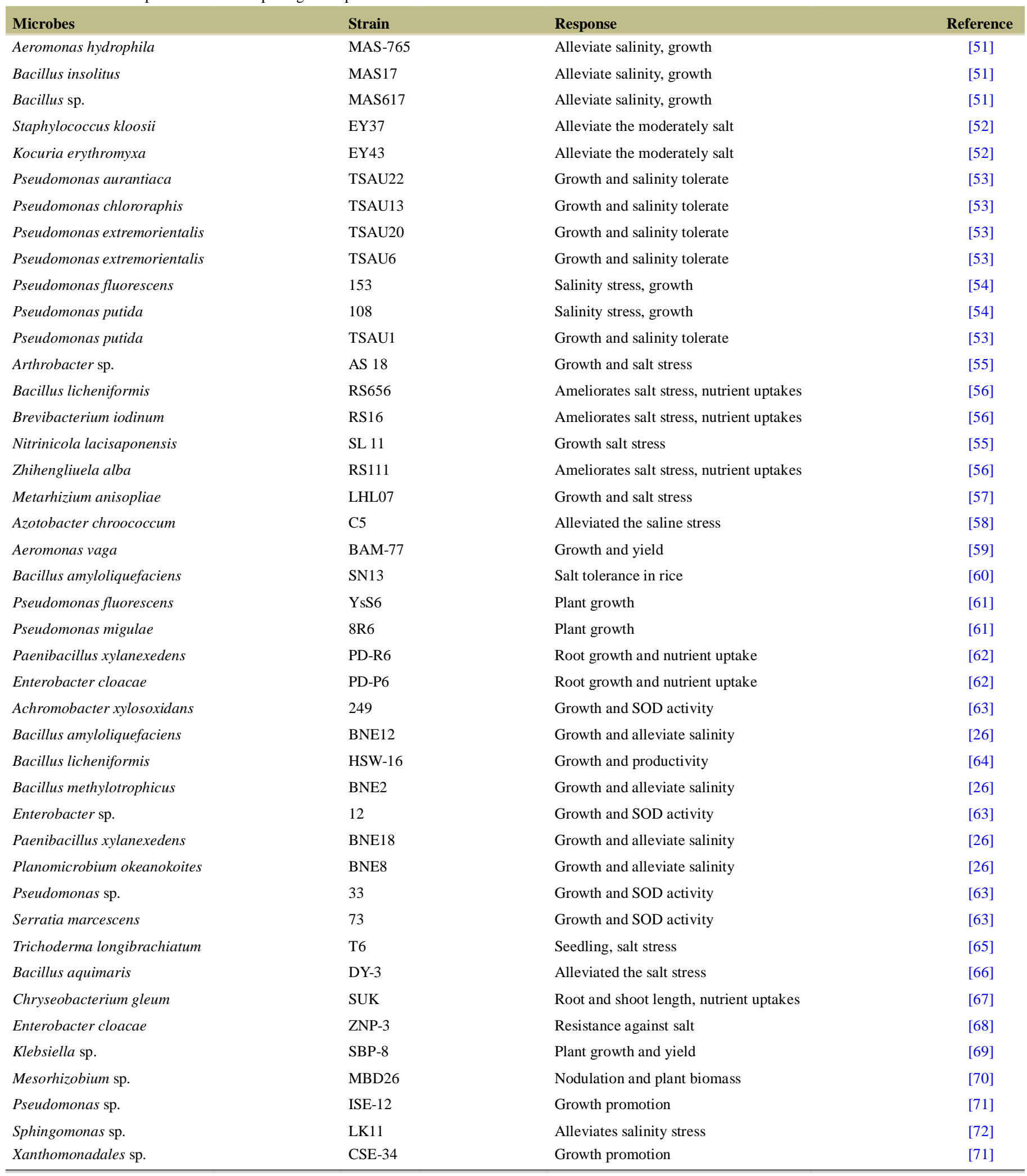

SOD: Superoxide dismutase

halophilic/halotolerant may promote plant growth in terms of increased seedling germination rates, roots and shoot length, biomass, nitrogen, phosphorus and potassium (NPK) content, chlorophyll content, protein content, yield, and tolerance to salinity stress. The microbiomes, the multifunctional PGP attributes, could be used as biofertilizers or bioinoculants which will be finally fit into long-term for high yield and soil fertility for sustainable agriculture. The soil salinity is one of the major limiting factors to plant growth and its productivity. Along with 
PGP microbes for growth and ameliorations of salinity stress, many other technologies have been implicated in the improvement of salt tolerance in crops. Sustainable agriculture requires the use of strategies to increase or maintain the current rate of food production. The PGP microbes as biofertilizers may alternative to conventional agricultural technologies.

The chemical fertilizers may be reduced by the use of microbes with multifunctional PGP attributes. The chemical fertilizers NPK are necessary for plant growth and high-yield productivity. The applications of these chemicals may be reduced/replaced by nitrogen-fixing, P-solubilizing, and K-solubilizing/mobilizing microbes (NPK) as biofertilizers an eco-friendly technologies without harming the environment for sustainable agriculture. The nitrogenfixing microbes (symbiotic, non-symbiotic, and free-living) such as Anabaena, Nostoc, Azospirillum, Azospirillium, Azotobacter, Beijerinckia, Clostridium, Drexia, Enterobacter, Gluconacetobacter, Klebsiella, Pseudomonas, and Rhizobium have been reported and characterized for biological nitrogen fixation under the saline conditions [34-36]. Among different micronutrients, phosphorus and potassium are essential for plant growth and development under the natural and harsh environmental conditions [29,37,38]. P-solubilization is a common attributes among different groups of microbes including haloarchaea (Haloarcula argentinensis, Haloferax alexandrinus, Haloferax larsenii, Haloferax volcanii, Halolamina pelagica, Halostagnicola kamekurae, Haloterrigena thermotolerans, and Natronoarchaeum mannanilyticum); halophilic bacteria (Azotobacter, Burkholderia, Citrobacter, Enterobacter, Pantoea,

and Pseudomonas); and salt-tolerant fungi (Aspergillus, Penicillium, Trichoderma, and Piriformospora) which have been isolated and characterized for P-solubilization [22,39-43]. K-solubilizing microbes such as Achromobacter, Arthrobacter, Bacillus, Duganella, Ensifer, Enterobacter, Exiguobacterium, Klebsiella, Lysinibacillus, Methylobacterium, Microbacterium, Ochrobactrum, Paenibacillus, Penicillium, Planococcus, Pseudomonas, Psychrobacter, Rhodobacter, Salmonella, Sphingobacterium, and Stenotrophomonas have been isolated and characterized for K-solubilization under in vitro and in vivo conditions [24,26,28,35,44].

The plant microbiomes produced different types of plant growthregulating hormones such as cytokinins and gibberellic acids and indole acetic acids. Indole acetic acids production is most common among all growth-regulating substances, and it has been produced by all types of plant-microbes interaction, for example, epiphytic, endophytic, and rhizospheric microbes. The gibberellic acids are most typical plant growth-regulating hormones, which have been produced by rhizospheric microbes, whereas cytokinins production has been reported by epiphytic/phyllospheric microbes. The production of such growth regulators by different groups of microbes provides numerous profits to the plants including the root growth, water absorption, and uptake of micronutrient from soil to plant and also ameliorates different abiotic stresses such as cold, heat, drought, and salinity. The plant microbiomes such as Arthrobacter, Azospirillum, Bacillus, Bradyrhizobium, Burkholderia, Enterobacter, Exiguobacterium, Lysinibacillus, Methylobacterium, Microbacterium, Ochrobactrum, Paenibacillus, Pantoea, Penicillium, Planococcus, Pseudomonas, Psychrobacter, Rhizobium, Rhodobacter, Salmonella, Sphingobacterium, and Stenotrophomonas have been reported to produced different PGP phytohormones [36,45,46].

The other PGP attributes for amelioration of salt stress are ACC deaminase activities by halophilic microbes. The microbes with ACC deaminase activities have the ability to decrease plant ethylene levels under the abiotic stress of salinity. Plant microbiomes such as Arthrobacter, Bacillus, Burkholderia, Enterobacter, Methylobacterium, Paenibacillus, Pantoea, Penicillium, Pseudomonas, Rhizobium, Rhodobacter, and Serratia have been reported as having the ability to decrease plant ethylene levels under the abiotic stress [35,44,45,47]. Along with direct PGP attributes, the plant microbiomes also possess some indirect PGP attributes such as the production of ammonia, hydrogen cyanide, siderophore (Fe-chelating compounds), antibiotics, antimicrobial substances, pigments, and some hydrolytic enzymes ( $\beta$-1, 3-glucanase, chitinases, pectinase and cellulase) [26,48,49]. These attributes help to protect crops from different plant pathogens and using these microbes as biocontrol in form of biofertilizers may increase crops productivity [50]. The most promising microbes which promote the plant through in-direct PGP mechanisms belong to different genera such as Aeromonas, Bacillus, Chryseobacterium, Enterobacter, Metarhizium, Nitrinicola, Planomicrobium, Pseudomonas, Sphingomonas, Trichoderma, Xanthomonadales, and Zhihengliuela $[34,41,45]$.

Biofertilizers are basically the microbes which basically bring about the enrichment of the nutrients of the soil by enhancement of the availability of the micronutrients to different cereal crops. The plant nutrients are one of the most essential components for sustainable agriculture. The production of the healthy crops so as to meet the demands of the world's expanding population mainly relies on the type of the fertilizers which are basically used to supplement all the nutrients to the plants, but more reliability on the chemical fertilizers is damaging the environmental ecology as well as affecting the human health with great severity. Thus, the use of the microbes as biofertilizers is considered as an alternative to chemical fertilizers so as to improve the fertility of the soil as well as increasing the productivity of the crops in sustainable farming. The plant microbiomes are considered to be the efficient and a novel tool for providing extensive benefits to the agriculture. The rhizospheric microbes basically colonize the roots and stimulate the growth under the natural as well as saline conditions. Halophilic microbes are contributing to the growth and sustenance of plants through various PGP activities under saline environments. These halophilic microbes help the plant in amelioration of salt stress and also promote the growth of plant and increase the soil fertility. There are many such reports on halophilic microbes including archaea, bacteria, and fungi used for ameliorations of salt stress and plant growth promotion for sustainable agriculture.

\section{CONCLUSION AND FUTURE PROSPECT}

Extreme environment is the major limiting factors to plant growth and its productivity. The research on salt tolerance microbiomes has been increased to improve crop growth and yield for sustainable agriculture. Potentially, PGP microbes can enhance plant resistance toward biotic and abiotic stresses as well as ameliorates the salt stress in crops. The microbes, the multiple PGP attributes, could be used as biofertilizers for high output yield to maintain the fertility of soil for sustainable agriculture. These potential PGP microbes will be ecofriendly from environments and human health. Hence, the research has to be focused on the discovery of novel and efficient microbial biodiversity from unexplored area such as hypersaline and drought region, which can be utilized for plant growth promotion and soil health. To replace the chemical NPK fertilizers, nitrogen-fixing, P-solubilizing, and K-solubilizing (NPK) microbiomes should be utilized as biofertilizers in large-scale crop production. In the future, the research on PGP mechanisms and its application for ameliorations of salt stress as well as in other biotechnological application such as 
microbe-mediated bioremediations and production of industrially and pharmaceutically important molecule from microbes harbor in diverse extreme environments will be increased. The beneficial microbes may be also screened for different probiotic attributes, which may be used for human health and nutrition. The research on microbiomes from extreme environments and plant microbiomes is very promising and will have noteworthy economic and environmental impacts in the future.

\section{ACKNOWLEDGMENT}

The authors duly acknowledge the Department of Biotechnology, Akal College of Agriculture and Vice Chancellor, Eternal University, for providing the motivation and research infrastructure.

\section{REFERENCES}

1. Yadav AN, Verma P, Kumar M, Pal KK, Dey R, Gupta A, et al. Diversity and phylogenetic profiling of niche-specific Bacilli from extreme environments of India. Ann Microbiol 2015;65:611-29.

2. Yadav AN, Verma P, Kour D, Rana KL, Kumar V, Singh B, et al. Plant microbiomes and its beneficial multifunctional plant growth promoting attributes. Int J Environ Sci Nat Resour 2017;3:1-8.

3. Yoshida M, Matsubara K, Kudo T, Horikoshi K. Actinopolyspora mortivallis sp. nov., a moderately halophilic actinomycete. Int J Syst Evol Microbiol 1991;41:15-20.

4. Cayol JL, Ollivier B, Patel BK, Prensier G, Guezennec J, Garcia JL. Isolation and characterization of Halothermothrix orenii gen. nov. sp. nov. a halophilic, thermophilic, fermentative, strictly anaerobic bacterium. Int J Syst Bacteriol 1994;44:534-40.

5. Xin H, Itoh T, Zhou P, Suzuki KI, Kamekura M, Nakase T. Natrinema versiforme sp. nov., an extremely halophilic archaeon from Aibi salt lake, Xinjiang, China. Int J Syst Evol Microbiol 2000;50:1297-303.

6. Yoon JH, Choi SH, Lee KC, Kho YH, Kang KH, Park YH. Halomonas marisflavae sp. nov. a halophilic bacterium isolated from the Yellow Sea in Korea. Int J Syst Evol Microbiol 2001;51:1171-7.

7. Yoon JH, Kim IG, Kang KH, Oh TK, Park YH. Bacillus marisflavi sp. nov. and Bacillus aquimaris sp. nov. isolated from sea water of a tidal flat of the Yellow Sea in Korea. Int J Syst Evol Microbiol 2003;53:1297-303.

8. Donachie SP, Bowman JP, On SL, Alam M. Arcobacter halophilus sp. nov. the first obligate halophile in the genus Arcobacter. Int J Syst Evol Microbiol 2005;55:1271-7.

9. Delgado O, Quillaguamán J, Bakhtiar S, Mattiasson B, Gessesse A, Hatti-Kaul R. Nesterenkonia aethiopica sp. nov., an alkaliphilic, moderate halophile isolated from an Ethiopian soda lake. Int J Syst Evol Microbiol 2006;56:1229-32.

10. Márquez MC, Carrasco IJ, Xue Y, Ma Y, Cowan DA, Jones BE, et al. Aquisalimonas asiatica gen. nov. sp. nov. a moderately halophilic bacterium isolated from an alkaline, saline lake in Inner Mongolia, China. Int J Syst Evol Microbiol 2007;57:1137-42.

11. Tang SK, Wang Y, Guan TW, Lee JC, Kim CJ, Li WJ. Amycolatopsis halophila sp. nov. a halophilic actinomycete isolated from a salt lake. Int J Syst Evol Microbiol 2010;60:1073-8.

12. Yang Y, Zou Z, He M, Wang G. Pontibacillus yanchengensis sp. nov., a moderately halophilic bacterium isolated from salt field soil. Int J Syst Evol Microbiol 2011;61:1906-11.

13. Ray L, Suar M, Pattnaik AK, Raina V. Streptomyces chilikensis sp. nov. a halophilic streptomycete isolated from brackish water sediment. Int J Syst Evol Microbiol 2013;63:2757-64.

14. Saker R, Bouras N, Meklat A, Zitouni A, Schumann P, Spröer C, et al. Prauserella isguenensis sp. nov. a halophilic actinomycete isolated from desert soil. Int J Syst Evol Microbiol 2015;65:1598-603.

15. Wu YH, Xamxidin M, Meng FX, Zhang XQ, Wang CS, Tohty D, et al. Marinirhabdus gelatinilytica gen. nov. sp. nov. isolated from seawater. Int J Syst Evol Microbiol 2016;66:3095-101.

16. Zhang G, Gu J, Zhang R, Rashid M, Haroon MF, Xun W, et al. Haloprofundus marisrubri gen. nov. sp. nov. an extremely halophilic archaeon isolated from a brine-seawater interface. Int J Syst Evol Microbiol 2017;67:9-16.

17. Saxena AK, Yadav AN, Rajawat M, Kaushik R, Kumar R, Kumar M, et al. Microbial diversity of extreme regions: An unseen heritage and wealth. Indian J Plant Genet Resour 2016;29:246-8.

18. Gaba S, Singh RN, Abrol S, Yadav AN, Saxena AK, Kaushik R. Draft genome sequence of Halolamina pelagica CDK2 isolated from natural salterns from Rann of Kutch, Gujarat, India. Genome Announc 2017;5:1-2.

19. Yadav AN, Verma P, Kaushik R, Dhaliwal HS, Saxena AK. Archaea endowed with plant growth promoting attributes. EC Microbiol 2017;8:294-8.

20. Chelius MK, Triplett EW. The diversity of Archaea and Bacteria in association with the roots of Zea mays L. Microb Ecol 2001;41:252-63.

21. Sun L, Qiu F, Zhang X, Dai X, Dong X, Song W. Endophytic bacterial diversity in rice (Oryza sativa $\mathrm{L}$.) roots estimated by $16 \mathrm{~S}$ rDNA sequence analysis. Microb Ecol 2008;55:415-24.

22. Yadav AN, Sharma D, Gulati S, Singh S, Dey R, Pal KK, et al. Haloarchaea endowed with phosphorus solubilization attribute implicated in phosphorus cycle. Sci Rep 2015;5:12293.

23. Yadav AN, Sachan SG, Verma P, Tyagi SP, Kaushik R, Saxena AK. Culturable diversity and functional annotation of psychrotrophic bacteria from cold desert of Leh Ladakh (India). World J Microbiol Biotechnol 2015;31:95-108.

24. Yadav AN, Verma P, Kumar V, Sangwan P, Mishra S, Neha P, et al. Biodiversity of the genus Penicillium in different habitats. In: New and Future Developments in Microbial Biotechnology and Bioengineering. Amsterdam: Elsevier; 2017.

25. Yadav AN, Verma P, Kumar V, Sachan SG, Saxena AK. Extreme cold environments: A suitable niche for selection of novel psychrotrophic microbes for biotechnological applications. Adv Biotechnol Microbiol 2017;2:1-4.

26. Verma P, Yadav AN, Khannam KS, Kumar S, Saxena AK, Suman A. Molecular diversity and multifarious plant growth promoting attributes of Bacilli associated with wheat (Triticum aestivum L.) rhizosphere from six diverse agro-ecological zones of India. J Basic Microbiol 2016;56:44-58.

27. Pandey S, Singh S, Yadav AN, Nain L, Saxena AK. Phylogenetic diversity and characterization of novel and efficient cellulase producing bacterial isolates from various extreme environments. Biosci Biotechnol Biochem 2013;77:1474-80.

28. Verma P, Yadav AN, Shukla L, Saxena AK, Suman A. Alleviation of cold stress in wheat seedlings by Bacillus amyloliquefaciens IARIHHS2-30, an endophytic psychrotolerant K-solubilizing bacterium from NW Indian Himalayas. Natl J Life Sci 2015;12:105-10.

29. Yadav AN, Verma P, Sachan SG, Saxena AK. Biodiversity and biotechnological applications of psychrotrophic microbes isolated from Indian Himalayan regions. EC Microbiol 2017;ECO.01:48-54.

30. Yadav AN, Sachan SG, Verma P, Saxena AK. Prospecting cold deserts of north western Himalayas for microbial diversity and plant growth promoting attributes. J Biosci Bioeng 2015;119:683-93.

31. Yadav AN, Rana KL, Kumar V, Dhaliwal HS. Phosphorus solubilizing endophytic microbes: Potential application for sustainable agriculture. EU Voice 2016;2:21-2.

32. Singh RN, Gaba S, Yadav AN, Gaur P, Gulati S, Kaushik R, et al. First high quality draft genome sequence of a plant growth promoting and cold active enzyme producing psychrotrophic Arthrobacter agilis strain L77. Stand Genomic Sci 2016;11:54.

33. Yadav AN, Verma P, Singh B, Chauhan VS, Sugitha T, Suman A, et al. Plant growth promoting bacteria: Biodiversity and multifunctional 
attributes for sustainable agriculture. Adv Biotechnol Microbiol 2017;5:1-17.

34. Verma P, Yadav AN, Khannam KS, Mishra S, Kumar S, Saxena AK, et al. Appraisal of diversity and functional attributes of thermotolerant wheat associated bacteria from the peninsular zone of India. Saudi J Biol Sci 2016. DOI: 10.1016/j.sjbs.2016.01.042.

35. Suman A, Yadav AN, Verma P. Endophytic microbes in crops: Diversity and beneficial impact for sustainable agriculture. In: Singh DP, Abhilash PC, Prabha R, editors. Microbial Inoculants in Sustainable Agricultural Productivity, Research Perspectives. India: Springer-Verlag; 2016. p. 117-43.

36. Verma P, Yadav AN, Kazy SK, Saxena AK, Suman A. Evaluating the diversity and phylogeny of plant growth promoting bacteria associated with wheat (Triticum aestivum) growing in central zone of India. Int J Curr Microbiol Appl Sci 2014;3:432-47.

37. Kumar V, Yadav AN, Verma P, Sangwan P, Saxena A, Kumar K, et al. B-propeller phytases: Diversity, catalytic attributes, current developments and potential biotechnological applications. Int J Biol Macromol 2017;98:595-609.

38. Kumar V, Yadav AN, Saxena A, Sangwan P, Dhaliwal HS. Unravelling rhizospheric diversity and potential of phytase producing microbes. SM J Biol 2016;2:1009.

39. Verma P, Yadav AN, Khannam KS, Panjiar N, Kumar S, Saxena AK, et al. Assessment of genetic diversity and plant growth promoting attributes of psychrotolerant bacteria allied with wheat (Triticum aestivum) from the northern hills zone of India. Ann Microbiol 2015;65:1885-99.

40. Vazquez P, Holguin G, Puente M, Lopez-Cortes A, Bashan Y. Phosphate-solubilizing microorganisms associated with the rhizosphere of mangroves in a semiarid coastal lagoon. Biol Fertil Soils 2000;30:460-8.

41. Yadav AN, Verma P, Kumar R, Kumar V, Kumar K. Current applications and future prospects of eco-friendly microbes. EU Voice 2017;3:21-2.

42. Verma P, Yadav AN, Kazy SK, Saxena AK, Suman A. Elucidating the diversity and plant growth promoting attributes of wheat (Triticum aestivum) associated acidotolerant bacteria from southern hills zone of India. Natl J Life Sci 2013;10:219-27.

43. Kaur R, Saxena A, Sangwan P, Yadav AN, Kumar V, Dhaliwal HS. Production and characterization of a neutral phytase of Penicillium oxalicum EUFR-3 isolated from Himalayan region. NUS Biosci 2017;9:68-76.

44. Yadav AN. Bacterial Diversity of Cold Deserts and Mining of Genes for Low Temperature Tolerance, Ph.D. Thesis. New Delhi, Ranchi: IARI, BIT; 2015. p. 234.

45. Yadav AN, Kumar V, Prasad R, Saxena AK, Dhaliwal HS. Microbiome in crops: Diversity, distribution and potential role in crops improvements. In: Prasad R, Gill SS, Tuteja N, editors. Crop Improvement through Microbial Biotechnology. Elsevier; 2017 (In press).

46. Suman A, Verma P, Yadav AN, Srinivasamurthy R, Singh A, Prasanna R. Development of hydrogel based bio-inoculant formulations and their impact on plant biometric parameters of wheat (Triticum aestivum L.). Int J Curr Microbiol Appl Sci 2016;5:890-901.

47. Glick BR. Introduction to plant growth-promoting bacteria. In: Beneficial Plant-Bacterial Interactions. Switzerland: Springer; 2015. p. 1-28.

48. Yadav AN, Sachan SG, Verma P, Saxena AK. Bioprospecting of plant growth promoting psychrotrophic Bacilli from the cold desert of north western Indian Himalayas. Indian J Exp Biol 2016;54:142-50.

49. Yadav AN, Sachan SG, Verma P, Kaushik R, Saxena AK. Cold active hydrolytic enzymes production by psychrotrophic Bacilli isolated from three sub-glacial lakes of NW Indian Himalayas. J Basic Microbiol 2016;56:294-307.
50. Verma P, Yadav AN, Kumar V, Khan MA, Saxena AK. Microbes in termite management: Potential role and strategies. In: Khan A, Ahmad W, editors. Sustainable Termite Management. Springer; 2017. DOI: org/10.1007/978-3-319-68726-1_9.

51. Ashraf M, Hasnain S, Berge O, Mahmood T. Inoculating wheat seedlings with exopolysaccharide-producing bacteria restricts sodium uptake and stimulates plant growth under salt stress. Biol Fertil Soils 2004;40:157-62.

52. Yildirim E, Turan M, Donmez MF. Mitigation of salt stress in radish (Raphanus sativus L.) by plant growth promoting rhizobacteria. Roum Biotechnol Lett 2008;13:3933-43.

53. Egamberdieva D, Kucharova Z. Selection for root colonising bacteria stimulating wheat growth in saline soils. Biol Fertil Soils 2009;45:563-71.

54. Abbaspoor A, Zabihi HR, Movafegh S, Asl MA. The efficiency of plant growth promoting rhizobacteria (PGPR) on yield and yield components of two varieties of wheat in salinity condition. Am Eurasian J Sustain Agric 2009;3:824-8.

55. Tiwari S, Singh P, Tiwari R, Meena KK, Yandigeri M, Singh DP, et al. Salt-tolerant rhizobacteria-mediated induced tolerance in wheat (Triticum aestivum) and chemical diversity in rhizosphere enhance plant growth. Biol Fertil Soils 2011;47:907.

56. Siddikee MA, Glick BR, Chauhan PS, Yim WJ, Sa T. Enhancement of growth and salt tolerance of red pepper seedlings (Capsicum annuum L.) by regulating stress ethylene synthesis with halotolerant bacteria containing 1-aminocyclopropane-1-carboxylic acid deaminase activity. Plant Physiol Biochem 2011;49:427-34.

57. Khan AL, Hamayun M, Khan SA, Kang SM, Shinwari ZK, Kamran M, et al. Pure culture of Metarhizium anisopliae LHL07 reprograms soybean to higher growth and mitigates salt stress. World J Microbiol Biotechnol 2012;28:1483-94.

58. Rojas-Tapias D, Moreno-Galván A, Pardo-Díaz S, Obando M, Rivera D, Bonilla R. Effect of inoculation with plant growthpromoting bacteria (PGPB) on amelioration of saline stress in maize (Zea mays). Appl Soil Ecol 2012;61:264-72.

59. Jha A, Saxena J, Sharma V. Investigation on phosphate solubilization potential of agricultural soil bacteria as affected by different phosphorus sources, temperature, salt, and $\mathrm{pH}$. Commun Soil Sci Plant Anal 2013;44:2443-58.

60. Nautiyal CS, Srivastava S, Chauhan PS, Seem K, Mishra A, Sopory SK. Plant growth-promoting bacteria Bacillus amyloliquefaciens NBRISN13 modulates gene expression profile of leaf and rhizosphere community in rice during salt stress. Plant Physiol Biochem 2013;66:1-9.

61. Ali S, Charles TC, Glick BR. Amelioration of high salinity stress damage by plant growth-promoting bacterial endophytes that contain ACC deaminase. Plant Physiol Biochem 2014;80:160-7.

62. Yaish MW, Antony I, Glick BR. Isolation and characterization of endophytic plant growth-promoting bacteria from date palm tree (Phoenix dactylifera L.) and their potential role in salinity tolerance. Antonie Van Leeuwenhoek 2015;107:1519-32.

63. Barra PJ, Inostroza NG, Acuña JJ, Mora ML, Crowley DE, Jorquera MA. Formulation of bacterial consortia from avocado (Persea americana Mill.) and their effect on growth, biomass and superoxide dismutase activity of wheat seedlings under salt stress. Appl Soil Ecol 2016;102:80-91.

64. Singh RP, Jha PN. A halotolerant bacterium Bacillus licheniformis HSW-16 augments induced systemic tolerance to salt stress in wheat plant (Triticum aestivum). Front Plant Sci 2016;7:1890.

65. Zhang S, Gan Y, Xu B. Application of plant-growth-promoting fungi Trichoderma longibrachiatum T6 enhances tolerance of wheat to salt stress through improvement of antioxidative defense system and gene expression. Front Plant Sci 2016;7:1405.

66. Li H, Jiang X. Inoculation with plant growth-promoting bacteria 
(PGPB) improves salt tolerance of maize seedling. Russ J Plant Physiol 2017;64:235-41.

67. Bhise KK, Bhagwat PK, Dandge PB. Synergistic effect of Chryseobacterium gleum sp. SUK with ACC deaminase activity in alleviation of salt stress and plant growth promotion in Triticum aestivum L 3. Biotech 2017;7:105.

68. Singh RP, Jha P, Jha PN. Bio-inoculation of plant growth-promoting rhizobacterium Enterobacter cloacae ZNP-3 increased resistance against salt and temperature stresses in wheat plant (Triticum aestivum L.). J Plant Growth Regul 2017. DOI: 10.1007/s00344-0179683-9.

69. Singh RP, Jha PN. Analysis of fatty acid composition of PGPR Klebsiella sp. SBP-8 and its role in ameliorating salt stress in wheat. Symbiosis 2017. DOI: 10.1007/s13199-017-0477-4.

70. Chaudhary D, Sindhu SS. Amelioration of salt stress in chickpea (Cicer arietinum L.) by coinculation of ACC deaminase-containing rhizospheric bacteria with Mesorhizobium strains. Legume Res Int J 2017;40:80-6.

71. Piernik A, Hrynkiewicz K, Wojciechowska A, Szymańska S, Lis MI, Muscolo A. Effect of halotolerant endophytic bacteria isolated from Salicornia europaea $\mathrm{L}$. on the growth of fodder beet (Beta vulgaris L.) under salt stress. Arch Agron Soil Sci 2017;63:1-15.

72. Khan AL, Waqas M, Asaf S, Kamran M, Shahzad R, Bilal S, et al. Plant growth-promoting endophyte Sphingomonas sp. LK11 alleviates salinity stress in Solanum pimpinellifolium. Environ Exp Bot 2017;133:58-69.

\section{How to cite this article:}

Yadav AN, Saxena AK. Biodiversity and biotechnological applications of halophilic microbes for sustainable agriculture. J App Biol Biotech.

2018;6(1):48-55. DOI: 10.7324/JABB.2018.60109 